\title{
Home as a Base for a Well-Lived Life: Comparing the Capabilities of Homeless Service Users in Housing First and the Staircase of Transition in Europe
}

\author{
Branagh R. O' Shaughnessy (D) ${ }^{a}$, Rachel M. Manning (D) ${ }^{a}$, Ronni Michelle Greenwood (D), \\ Maria João Vargas-Moniz (D) ${ }^{b}$, Sandrine Loubière (DiD ${ }^{c}$, Freek Spinnewijn ${ }^{d}$, \\ Marta Gaboardi (D) ${ }^{\mathrm{e}}$, Judith R. Wolf (D) ${ }^{f}$, Anna Bokszczanin (iD ${ }^{\mathrm{g}}$, Roberto Bernad (iD) ${ }^{\mathrm{h}}$, \\ Mats Blid (iD', Jose Ornelas (D) ${ }^{b}$ and The HOME-EU Consortium Study Group*
}

\begin{abstract}
aDepartment of Psychology, University of Limerick, Limerick, Ireland; ${ }^{\mathrm{b}} \mathrm{APPsyCl}$ - Applied Psychology Research Center Capabilities and Inclusion, ISPA-Instituto Universitário, Lisbon, Portugal; 'Department of Research and Innovation, Support Unit for Clinical Research and Economic Evaluation, Assistance PubliqueHôpitaux De Marseille, Marseille, France; 'European Federation of National Organisations Working with the Homeless (FEANTSA), Brussels, Belgium; 'Department of Developmental and Social Psychology, University of

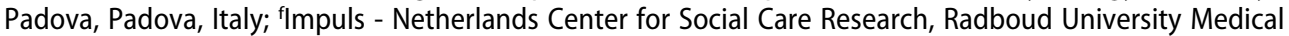
Center, Radboud Institute for Health Sciences, Nijmegen, The Netherlands; IInstitute of Psychology, Opole University, Opole, Poland; 'RRais Fundación, Madrid, Spain; 'Mid Sweden University, Östersund, Sweden
\end{abstract}

\begin{abstract}
Nussbaum's Central Capabilities refer to the elements of a well-lived life, and many adults who experience homelessness are deprived of these capabilities. The study aim was to investigate whether service users experience different homeless services as affording or constraining capabilities. We conducted semi-structured interviews with homeless service users $(n=77)$ in Housing First (HF) and staircase services (SS) in eight European countries. We used thematic analysis to identify three themes: autonomy and dependency, the relational impact of living arrangements, and community interaction and stigma. While SS participants were able to address their bodily integrity and health, their higherorder capabilities were constrained by their homeless situations. HF participants described home as a base from which they could enact a wide range of capabilities indicative of a well-lived life. We conclude that housing-led service models with appropriate supports are key to affording service users' capabilities. Practical and policy implications are discussed.
\end{abstract}

\section{ARTICLE HISTORY}

Received 8 November 2019

Accepted 23 April 2020

\section{KEYWORDS}

Capabilities approach; Housing First; homelessness; ontological security; Europe

\section{Introduction}

The capabilities approach (CA) was developed by economist-philosopher, Amartya Sen (1980), who argued that in a minimally just society its citizens are free to exercise the capabilities of their choosing, and this freedom should be an indicator of human development (Nussbaum 2011, Chapter 3). According to the CA, what people are free to do and

CONTACT Branagh R. O' Shaughnessy branaghros@gmail.com Department of Psychology, University of Limerick, Castletroy, Limerick, V94 T9PX, Ireland

*HOME-EU Consortium Study Group membership is detailed in acknowledgements.

(c) 2020 IBF, The Institute for Housing and Urban Research 
to be (i.e., their "freedoms"), as well as what they actually do (i.e., their "functionings") are indicators of social justice and well-being (Smith 2010; Sen 2005). Nussbaum (2011) distinguished capabilities, as freedoms to do and to be, from functionings, as the outcomes of these freedoms. For example, freedom to practice one's religion is a capability, while the specific religion practiced is a functioning (Batterham 2019). Informed by Sen's (2004) view that some "basic capabilities ... will no doubt figure in every list of relevant capabilities in every society", Nussbaum (2011) proposed ten central capabilities: life; bodily health; bodily integrity; affiliation; other species; play; senses, imagination, and thought; emotions; practical reason; and control over one's environment (see Table 1 for definitions). These ten central capabilities refer to the basic elements of freedom and agency, but also extend to incorporate meaningful connections with others and creative thought, for example. Each capability is inherently valuable and interdependent on the others, and while this list is not exhaustive, it highlights each capability as a minimal base from which people can meaningfully express agency and live valued lives.

The CA is sensitive to the complex relationship between individual agency and social, cultural, political, and economic structures (Smith and Seward 2009). Just as context can shape the kinds of capabilities afforded to an individual, an individual's attributes can interact with their context to shape their capabilities. An example of one such individual attribute is a strong work ethic. A strong work ethic is likely to lead to gainful employment (under favourable economic conditions), which in turn facilitates a wide variety of capabilities, such as practical reason and material control over one's environment. In contrast, a person unable to work due to a physical disability may experience numerous constraints on their capabilities due to a lack of income. However, if they have access to adequate and supportive health and welfare services, it may mitigate some of the constraints they experience. Guided by this ecological perspective, homeless interventions researchers

Table 1. Descriptions of the Central Capabilities.

\begin{tabular}{|c|c|}
\hline Life & $\begin{array}{l}\text { To have a life worth living and to not die a premature death, for example from illnesses } \\
\text { associated with rough sleeping. }\end{array}$ \\
\hline Bodily integrity & $\begin{array}{l}\text { To feel safe and be protected from any kind of violence, be it physical, sexual or domestic. To } \\
\text { be free to make reproductive choices and have opportunities for sexual satisfaction. }\end{array}$ \\
\hline Affiliation & $\begin{array}{l}\text { (A) To have a variety of social interactions, show empathy, and care for and co-exist with } \\
\text { others. For example, by maintaining relationships with family members. } \\
\text { (B) To respect oneself and not feel ashamed. To be treated with dignity, for example, to } \\
\text { not be treated as deficient because of being in a homeless situation. }\end{array}$ \\
\hline Play & To feel joy, have fun and engage in pastimes. \\
\hline $\begin{array}{l}\text { Senses, imagination, } \\
\quad \& \text { thought }\end{array}$ & $\begin{array}{l}\text { To engage in activities that stimulate thought, senses and imagination, such as education, } \\
\text { and creative arts. To have freedom of speech and the freedom to practice one's religious } \\
\text { faith. To be free to experience pleasure and avoid non-beneficial pain. }\end{array}$ \\
\hline Other species & $\begin{array}{l}\text { To be able to enjoy and appreciate animals, plants, and the world of nature, for example by } \\
\text { keeping a pet. }\end{array}$ \\
\hline Bodily health & To have adequate shelter, good physical health, and to be adequately nourished. \\
\hline Emotions & $\begin{array}{l}\text { Not having one's emotional development overshadowed by fear and anxiety, for example } \\
\text { anxiety due to being without a home. To be able to experience love, grief, longing, } \\
\text { gratitude, and justified anger. }\end{array}$ \\
\hline $\begin{array}{l}\text { Practical reason } \\
\text { Control over one's } \\
\quad \text { environment }\end{array}$ & $\begin{array}{l}\text { To be able to reflect on and plan one's future. To be able to engage in critical thinking. } \\
\text { (A) Political: To participate in the political process, and exercise democratic rights as } \\
\text { citizens, for example, through voting in elections. } \\
\text { (B) Material: To gain economic independence including through employment and owning } \\
\text { property, or where this is not possible, to have control over the space where one } \\
\text { resides. }\end{array}$ \\
\hline
\end{tabular}

Note: descriptions adapted from Nussbaum (2011). 
have successfully applied the CA to examine the role of home (Nicholls 2010), workfocused social enterprises (Tanekenov, Fitzpatrick and Johnsen 2018), and to describe a capabilities-enhancing supported housing programme (Shinn 2015). These studies have highlighted the utility of the CA for scrutinising contextual influences on the perceptions, choices, and perceived options of homeless service users.

\section{Capabilities and Homelessness}

Nussbaum (2011) regarded the central capabilities as human rights, which aligns them with a rights-based approach for understanding and addressing homelessness. Central to a rights-based approach is housing as "a fundamental necessity to which all persons need access in order to maintain a basic level of dignity, and have an opportunity to achieve their full potential as human beings" (Byrne and Culhane 2011, 381). Indeed, Waldron (as quoted in King, 2003) described the experience of homelessness as having no place to "be", and Padgett (2007) described how, for adults with histories of homelessness, home was synonymous with feelings of ontological security. Drawing from Giddens, 1990, and Laing, 1965 (quoted in Padgett 2007), Padgett (2007) described ontological security as a psychological sense of stability derived from a sense of constancy in one's material and social context, which acts as base for self-expression and personal development. There is overlap between this concepualisation of ontological security and the CA: the CA incorporates the basic freedoms associated with a well-lived life, including the freedom of self-expression, and its inclusion of the social and material contexts that shape these freedoms aligns the CA with concepts of self-actualisation, identity and the social and material milieu described by Padgett (2007). Therefore, homelessness is an example of extreme injustice: it denies the individual the basic elements of a life well-lived, the stability and privacy associated with having a home, and freedom to pursue self-actualisation.

It is easy to infer how the experience of homelessness might constrain certain capabilities. Mortality rates among homeless individuals are much higher than that of the general population (life; Hwang et al. 2009; Roncarati et al. 2018). Similarly, individuals experiencing homelessness have limited access to adequate shelter and nutrition, as well as more exposure to assault and violence (bodily health and integrity; Goodman, Dutton, and Harris 1995; Hopper et al. 1997; Nussbaum 2011). Individuals experiencing homelessness also tend to be isolated from housed community members and from wider society (affiliations; Ware et al. 2007).

The constraining influence of homelessness on a person's ability to live a well-lived life has received attention in the literature, for example, Evangelista (2010) argued that adequate housing is a necessary precondition for the achievement of central capabilities. Nicholls (2010) applied the capabilities approach to the experiences of adults transitioning through homelessness, and indicated that while access to housing improved participants' material circumstances and related capabilities, many still experienced constraints on capabilities such as play and affiliation. Homelessness can have a detrimental impact on a person's capabilities, and the role of housing and shelter for addressing these capabilities-deficits requires further investigation. 


\section{Homeless Services: Affording or Constraining Capabilities?}

Mainstream homeless services in Europe follow a staircase of transition approach, which is comprised of a series of supportive living arrangements. The "staircase" refers to the transition from living on the street, to low-grade shelter accommodation, followed by transitional housing (Sahlin 2005). The structure of living arrangement varies in intensity depending on the service user's "housing readiness" (Gulcur et al. 2003, 172), and often involves structured congregate living arrangements where the configuration of supports is determined by service providers (Team, Homeless Link Policy and Research 2015; Centre for Social Justice 2017). Homeless adults enter the staircase through a variety of services, such as drop-in centres or shelters. Entry to shelter services requires a detailed biographical interview so that service providers can establish the reason why the individual is homeless, and co-ordinate supports to address this reason (Lyon-Callo 2000). The individual is expected to comply with their prescribed support plan which may involve psychiatric or addiction treatment. If the individual transitions to shelter accommodation, their daily routine involves regimented meal and recreational times, while co-habitation, having pets, and hosting visitors are prohibited (Stark 1994). In Europe and North America, some shelters only operate at night, which means that service users are left searching for sustenance and shelter for 12 hours of the day. If service users comply with treatment plans and programme rules, they can graduate up the staircase and back towards normal unsupported living arrangements (Sahlin 2005). If they cannot abide by these rules, service users tend to remain where they are or, in some cases, regress further down the staircase towards homelessness (Sahlin 2005). As such, staircase services are underpinned by a philosophy of moral worthiness and housing readiness (Hopper et al. 1997; Gulcur et al. 2003; Tsemberis, Gulcur, and Nakae 2004).

Although staircase services (SS) are widespread, experts (e.g. Sahlin 2005; Tsemberis and Eisenberg 2000; Busch-Geertsema and Sahlin 2007; Ridgway and Zipple 1990) have questioned their efficacy in ending homelessness. Research shows that many individuals are unable or unwilling to comply with the rules and so they fail to progress through the staircase (Hopper et al. 1997). As noted, noncompliance can lead to eviction and some individuals end up cycling through various institutional circuits (Hopper et al. 1997). Nicholls (2010) suggested that staircase services afford services users' bodily health and integrity but at the expense of their control over environment, which underpinned their freedom: how they lived their life, and what they could do or could be. Similarly, in a study that compared the experiences of service users in emergency shelters with those in housing, Kerman and Sylvestre (2019) reported that shelter users were able to address bodily health and integrity, but the restrictions associated with shelter life did little else to improve their lives. In a study of the capabilities and resilience of homeless service users, Smith (2010) indicated that while staircase services were initially supportive and allowed people in homelessness to address bodily health and integrity, staying there long-term was inappropriate. Instead, permanent housing allowed service users to build new relationships and better themselves educationally, creatively and financially (Smith 2010).

Housing First (HF) is a housing-led model of service provision for adults with complex needs in long-term homelessness (Tsemberis 2010). The HF model differs 
from the staircase model because it supports adults experiencing homelessness to choose private, time-unlimited homes within community settings, rather than to prove their housing readiness (Gulcur et al. 2003). In addition to choosing their homes, HF service users are supported to make choices about their recovery and daily living activities (Tsemberis and Eisenberg 2000; Tsemberis, Gulcur, and Nakae 2004). Shinn (2015) has described the potential of HF as a capability-enhancing programme, through its provision of housing without treatment or sobriety requirements, and its emphasis on consumer control over services, it offers service users a base to nurture life and bodily health capabilities, without sacrificing their environmental control. In Padgett's (2007) qualitative study of the meaning of home, participants in HF had a sense of control, established daily routines, enjoyed privacy, and took the opportunity to engage in identity construction and repair. Other evidence suggests that HF is more effective than staircase services at promoting recovery in terms of housing stability, psychiatric symptoms, and community integration (Aubry, Nelson, and Tsemberis 2015; Busch-Geertsema 2014), but the experiences of service users in HF have not yet been examined using the capabilities approach framework.

\section{The Present Research}

Given the ecological influences on capabilities, it is important to consider how homeless service users experience HF and SS as capabilities-enhancing or constraining. Therefore, our objective was to identify and compare the constraints and affordances on capabilities experienced by service users in SS and HF programmes in Europe.

\section{Method}

\section{Study Context}

This study is part of a larger project called "Homelessness as Unfairness" (HOME_EU), a European Commission-funded study of long-term homelessness in Europe. Composed of twelve consortium partners and representing eight European countries, this project integrates the perspectives of citizens, service users, service providers, and socio-political stakeholders to understand the ways homelessness is sustained, and to identify the ways it can be reversed. In the present study, we used qualitative methods to examine the experiences of homeless service users in staircase and Housing First homeless services in eight European countries: France, Ireland, Italy, The Netherlands, Poland, Portugal, Spain, and Sweden. We used a qualitative approach to meet our objective because it allowed us to gather rich and in-depth accounts of participants' experiences (Geertz 1973).

The leaders of the service users' study, who were based in Ireland, developed a protocol that was followed by participating research teams. The protocol, described elsewhere (Greenwood, Manning, O'Shaughnessy, Cross, et al. 2020) included guidance for participant recruitment, consent, interview schedule administration, and analysis. We used this protocol together with biannual meetings, and regular communication with study consortium partners to help standardise study activities across the eight countries and reduce inconsistencies in procedural implementation. 


\section{Eligibility and Recruitment}

\section{Programme Selection}

Research teams in each country identified HF programmes according to study protocol (Greenwood, Manning, O'Shaughnessy, Cross, et al. 2020), which stipulated that eligible programmes followed the principles of the Pathways Housing First model (Tsemberis, Gulcur, and Nakae 2004). Participants in SS were recruited from temporary shelter accommodation, women's refuges, drop-in psychiatric services, and night shelters, for example. The protocol stipulated that SS programmes do not identify as HF and do not meet HF criteria on dimensions including housing type, eligibility requirements, and/or abstinence or treatment requirements.

\section{Participant Eligibility and Recruitment}

Participants were recruited in each country from a larger, multi-method study of service users' recovery experiences, as part of the HOME_EU project, and which included adults in homeless situations who used HF and SS. Each team was instructed to recruit five participants each from the HF and SS sample of their country, to incorporate a wide range of genders and ages in their sample, and to select participants who showed high engagement with the quantitative component of the study. Because participants were selected on the basis of their ability to participate in an in-depth qualitative interview, it is possible that this inclusion criterion set them apart from other service users experiencing higher levels of chaos in their lives. Thus, the kinds of experiences reported by the participants in this study may only partially represent that of service users in poorer circumstances.

At the time interviews were conducted, Poland did not have a HF programme, so participants were recruited only from SS in Poland. In Sweden, due to challenges with following up with participants from the multi-method study sample, a unique sample of service users were recruited who were demographically similar to the rest of the sample based on age, gender, number of children, education, and marital status (see Table 2).

Table 2. Participant characteristics.

\begin{tabular}{|c|c|c|c|c|}
\hline \multirow[b]{2}{*}{ Characteristic } & \multicolumn{2}{|c|}{$\begin{array}{l}\text { Housing First } \\
\quad(n=37)\end{array}$} & \multicolumn{2}{|c|}{$\begin{array}{c}\text { Staircase Services } \\
(n=40)\end{array}$} \\
\hline & $n / M$ & $\% / S D$ & $n / M$ & $\% / S D$ \\
\hline \multicolumn{5}{|l|}{ Gender } \\
\hline Male & 24 & 64.9 & 29 & 72.5 \\
\hline Female & 13 & 35.1 & 11 & 27.5 \\
\hline Age & 49.32 & 7.41 & 47.3 & 12.6 \\
\hline Marital status: Single & 21 & 63.6 & 20 & 58.8 \\
\hline \multicolumn{5}{|l|}{ No. of children } \\
\hline 0 & 22 & 59.5 & 22 & 55 \\
\hline $1+$ & 15 & 40.5 & 18 & 45 \\
\hline \multicolumn{5}{|l|}{ Education $^{\mathbf{a}}$} \\
\hline Primary level & 19 & 51.4 & 28 & 70 \\
\hline Secondary level & 10 & 27 & 9 & 22.5 \\
\hline Third level & 7 & 18.9 & 2 & 5 \\
\hline Employment status: Unemployed & 26 & 76.5 & 28 & 82.4 \\
\hline Physical health issue & 21 & 56.8 & 20 & 50 \\
\hline Mental health issue & 14 & 37.8 & 18 & 45 \\
\hline Addiction issue & 20 & 54.1 & 19 & 47.5 \\
\hline Lifetime homelessness (months) & 74.78 & 91.74 & 107.79 & 114.87 \\
\hline
\end{tabular}

${ }^{\mathrm{a}}$ Data missing for one participant in $\mathrm{HF}$, and one in SS $(n=2)$. 


\section{Materials and Procedure}

We developed a semi-structured interview schedule based on Sen $(1992,1999)$ and Nussbaum's (2011) conceptions of the capabilities approach. The main purpose of the interview schedule was to understand the "range of realistic possibilities" (Shinn 2015, 249), that is, the capability set that was available to participants within HF and SS. We used Nicholls's (2010) conceptualisation of control over one's environment, because, for adults in homelessness, the ownership of property (as conceptualised by Nussbaum 2011) is not feasible, so instead we conceptualised material control over one's environment as control over one's living space. We followed Shinn's (2015) suggestions to examine these capabilities in terms of participants' functionings, freedoms, internal and external constraints, and internal and external affordances. Interviewers asked participants about how their homeless service, either SS or HF, facilitated or constrained capabilities in each domain. For example, to capture bodily integrity, interviewers introduced the topic as feelings of safety, and being free from violence, or any kind of abuse, such as verbal, psychological, physical, or sexual abuse, followed by more specific questions such as, "what things do you choose to do to improve your personal safety?", and "what kinds of things are you not currently able to do, but you would like to do, to improve your personal safety?". Each partner country was responsible for the translation of interview materials to their respective languages according to standardised translation and back translation procedures (Beaton et al. 2000). The consortium leaders received ethical approval for study activities from their institutional Ethical Review Board (ERB), and each consortium partner was granted approval from their ERB, either by submitting confirmation of approval from the lead consortium partner or by submitting an individual application in accordance with their ERB's requirements. Interviewers met with service users in a private space such as their home, or an office space at the homeless service they used. Interviewers described the study in detail and recorded service users' consent to participate. Participants completed a short demographic survey and interviewers asked questions according to the semi-structured interview schedule. Interviews were audio recorded and participants were given a $€ 20$ shopping voucher for taking part.

\section{Data Analysis}

In each country, interviews were transcribed verbatim and anonymised. We followed Braun and Clarke's (Braun and Clarke 2006) stages of thematic analysis in our investigation. These stages were: 1. Familiarisation with the data 1. Generate initial codes, 2. Search themes, 3. Define themes, 4. Review themes. In each country, two coders worked independently to generate the initial codes, which referred to each capabilities dimension, internal and external affordances and constraints, and actions taken or not taken by participants. Once initial coding was complete, coders met to review and to agree on any discrepancies in the codes. Bilingual members of each consortium research team translated all coded text excerpts back to English using standardised procedures (Beaton et al. 2000). Following this, two researchers met again to agree on the translation. This standardised translation procedure, and the proficiency and intercultural competence of translators ensured that the intended meaning of participants' accounts, and of interview questions was retained throughout the study, and minimised any potential limitations 
caused by translation and back translation procedures across eight languages, which in turn allowed us to represent a wide range of sociocultural perspectives in our data.

Partners returned their codes to the study leaders who collated all coded excerpts in qualitative analysis software, NVIVO (version 12). To add interpretive depth to the first round of codes, the first author generated a second round of codes based on the topic and implicit meaning of participant statements. Country specific coding was retained throughout the second phase of coding: for example, the second round code of "friendship" referred to an extract also coded as "affiliation", "choose to do", and "external affordance" in the first round of coding. Following additional guidelines by Miles, Michael Huberman, and Saldana (2014) and Bazeley (2009), the first author arranged secondary codes into themes by consolidating, renaming and grouping codes into themes and sub-themes based on the study aim, and based on topics most commonly discussed by participants. To define and refine themes, the first author wrote descriptive outlines of each theme and sub-theme, with extracts, and met with the third author to agree on themes and illustrative extracts as representative of the data, and effective for addressing the study aim.

\section{Programmes and Participants}

\section{Participants}

A total of 78 participants, 37 HF service users and 41 SS users, completed interviews. Teams in Ireland, Italy, The Netherlands, Portugal, Spain, and Sweden completed interviews with five participants in HF and five participants in SS. In France and Portugal, six interviews were completed with HF participants, and four with SS participants, and in Poland, eight participants were interviewed who were in SS. One participant in France was omitted from the analysis because they were not receiving homeless services at the time of the interview, and this left a total sample of 77 (HF: $n=37$; SS: $n=40$ ) participants. Overall, participants were mostly male $(n=53,68.8 \%)$, and on average, 48.27 years old (range $=20-65, S D=10.42)$. Most participants $(61.2 \%)$ were single, less than half $(42.9 \%)$ had one or more children $(M=0.97, S D=1.48$, range $=0-7)$, and just $3.9 \%(n=3)$ had custody of their children. Most had primary level education (64.7\%) and were unemployed (79.4\%). See Table 2 for a detailed presentation of participant characteristics according to service type. We ran independent samples $t$-tests, and Pearson's Chi-Squared tests of independence to assess if the groups differed according to participant characteristics, and results indicated that the groups were similar on all participant characteristics.

\section{Programmes}

Across the eight countries, participants were recruited from 17 different HF programmes and 21 different SS programmes. Scatter-site housing was the primary form of housing provided by HF programmes (86.5\%), and congregate accommodation was the primary form of housing provided by SS programmes (85\%). In terms of support, $45.2 \%(n=25)$ of HF participants received either Assertive Community Treatment (ACT) or Intensive Case Management services, while $16.2 \%(n=6)$ received another form of support. For SS participants, $15 \%(n=6)$ received ACT and $27.5 \%(n=11)$ received another form of support. Data on 
support type were missing for the rest of participants in HF $(16.2 \%, n=6)$ and SS $(57.5 \%$, $n=23)$.

\section{Results}

We identified three overarching themes that best represented service users' experiences: autonomy and dependency, relational impact of living arrangements, and community interaction and stigma. These themes are organised according to the capabilities dimensions they correspond with in Table 3. We describe each theme according to its related subthemes, except for community integration and stigma, which consisted of a single theme. To ensure anonymity, participants' interview excerpts are identified by country, service group and three unique digits.

\section{Autonomy and Dependency}

\section{Security of a Front Door}

HF participants spoke positively about the freedom and security they derived from residing alone within four secure walls and from being able to close and lock their front door as they wished: "Now I have a security door that I can close and be by myself. [...]. This is my monastery. [...] I feel absolutely safe ... it was a little more like a symbol, the door" (Sweden, HF008). For HF participants, having their own front door was important for their sense of security, and for gatekeeping who could enter their space, as illustrated by the following quote: "there are a lot of people on the street which can be very messy but I have a little hole where I can stay. There, nobody hurts me, only if I open the door and I let someone inside" (Portugal, HF010).

Access to and control over a door was not a luxury afforded to SS participants, who described living in fear because they could not control who entered their living space, could not lock away personal belongings, and could not lock the door of their room: "You cannot feel safe in a place like this" (Sweden, SS002). Some SS participants were always on edge, afraid of having their belongings stolen or incurring an attack: "two years ago I was attacked by someone" (Italy, SS212). The insecure congregate living structure of SS denied these participants the freedom to control who entered their space, and the basic safety and security of their person and belongings, which in turn constrained their bodily integrity, emotions, affiliation and control over environment capabilities. However, HF participants used their home as a "sanctuary" where they could freely exercise bodily integrity, emotions, control over environment, and affiliation capabilities.

Having tenancy in their own home contributed to HF participants' sense of security, especially compared to their formerly insecure living arrangements in SS, as illustrated by the following quote: "I knew I couldn't lose this place ... [...] When you're in a hostel, [...] if you stop paying your rent, you get kicked out [...]. This [home] is mine until the day I die" (Ireland, HF456). Instead of being afraid of losing the roof over their head, HF participants felt secure and stable which allowed them to focus on other aspects of a well-lived life such as work, education, and family relationships, as shown in these accounts:

I will regain [custody of daughter], as soon as I am in the right circumstances: work and a more stable life, permanent stability. I will get my daughter back! (Portugal, HF006) 
Table 3. Themes of affordances and constraints on capabilities.

\begin{tabular}{|c|c|c|c|}
\hline $\begin{array}{l}\text { Theme } \\
\text { Sub-theme }\end{array}$ & Service & Capabilities Affordances/Constraints & Related service features \\
\hline \multirow[t]{2}{*}{$\begin{array}{l}\text { Autonomy \& } \\
\text { Dependency } \\
\text { Security of } \\
\text { a front door }\end{array}$} & $\mathrm{HF}$ & $\begin{array}{l}\text { Afforded bodily integrity, control over one's } \\
\text { environment, emotions, senses, imagination } \\
\text { and thought, practical reason, and affiliation. }\end{array}$ & $\begin{array}{l}\text { - Being able to close and lock } \\
\text { a front door } \\
\text { - Having a secure space to store } \\
\text { belongings } \\
\text { - Using a door to control who } \\
\text { enters the living space } \\
\text { - Having tenancy in one's own } \\
\text { home }\end{array}$ \\
\hline & SS & $\begin{array}{l}\text { Afforded bodily integrity. } \\
\text { Constrained bodily integrity, emotions, } \\
\text { affiliation, senses, imagination and thought, } \\
\text { practical reason, and control over one's } \\
\text { environment }\end{array}$ & $\begin{array}{l}\text { - Access to shelter and basic needs } \\
\text { facilities } \\
\text { - No door and no secure storage } \\
\text { space } \\
\text { - Unsafe and exposed to threats } \\
\text { (e.g. violence and thievery) } \\
\text { - No choice over who one lives with } \\
\text { - No secure tenancy } \\
\text { - Use of night shelters meant } \\
\text { nowhere to go during the day }\end{array}$ \\
\hline \multirow[t]{2}{*}{$\begin{array}{l}\text { Rules \& everyday } \\
\quad \text { life }\end{array}$} & $\mathrm{HF}$ & $\begin{array}{l}\text { Afforded life, control over environment, play, } \\
\text { emotions, senses, imagination and thought, } \\
\text { bodily health, bodily integrity, affiliation, and } \\
\text { practical reason }\end{array}$ & $\begin{array}{l}\text { - Being able to relax and enjoy pas- } \\
\text { times at home } \\
\text { - To set and follow one's own rou- } \\
\text { tine and to carry out daily living } \\
\text { tasks (e.g. cooking and recreation) }\end{array}$ \\
\hline & SS & $\begin{array}{l}\text { Constrained life, control over one's environment, } \\
\text { play, emotions, affiliation, practical reason, } \\
\text { bodily integrity, and bodily health }\end{array}$ & $\begin{array}{l}\text { - Scheduled mealtimes and poor- } \\
\text { quality food } \\
\text { - Strict curfew and regulated time } \\
\text { outside the service } \\
\text { - Supervision of daily living tasks }\end{array}$ \\
\hline \multirow[t]{2}{*}{$\begin{array}{l}\text { Transformative } \\
\text { impact of } \\
\text { home }\end{array}$} & $\mathrm{HF}$ & $\begin{array}{l}\text { Afforded life, emotions, and bodily health and } \\
\text { integrity. }\end{array}$ & $\begin{array}{l}\text { - Exit from homelessness } \\
\text { - Stability and permanence } \\
\text { - Opportunity for a fresh start }\end{array}$ \\
\hline & SS & $\begin{array}{l}\text { Constrained life, emotions, and control over one's } \\
\text { environment. }\end{array}$ & $\begin{array}{l}\text { - No stability or permanence } \\
\text { - No address creating difficulties } \\
\text { with formal administration } \\
\text { - Conflicting demands of social and } \\
\text { housing services }\end{array}$ \\
\hline $\begin{array}{l}\text { Relational } \\
\text { impact of } \\
\text { living }\end{array}$ & $\mathrm{HF}$ & $\begin{array}{l}\text { Afforded affiliation, life, control over one's } \\
\text { environment, bodily integrity, emotions, and } \\
\text { senses, imagination and thought. }\end{array}$ & $\begin{array}{l}\text { - Live with or nearby family or } \\
\text { romantic partner } \\
\text { - Participate in family life }\end{array}$ \\
\hline $\begin{array}{l}\text { arrangements } \\
\text { Familial \& } \\
\text { intimate } \\
\text { relationships }\end{array}$ & SS & $\begin{array}{l}\text { Constrained life, emotions, affiliation, bodily } \\
\text { integrity, senses, imagination and thought, and } \\
\text { control over one's environment. }\end{array}$ & $\begin{array}{l}\text { - Children not permitted in service } \\
\text { setting } \\
\text { - Restrictions on time spent outside } \\
\text { of the service } \\
\text { - Curfew, and lack of privacy } \\
\text { - Conceal sexuality due to risk of } \\
\text { exposure to homophobia }\end{array}$ \\
\hline \multirow[t]{2}{*}{ Friendship } & $\mathrm{HF}$ & $\begin{array}{l}\text { Afforded control over environment, affiliation, and } \\
\text { practical reason. } \\
\text { Constrained affiliation }\end{array}$ & $\begin{array}{l}\text { - Control over who one lives with } \\
\text { - Control over relational activities } \\
\text { (e.g. who can come and visit) } \\
\text { - Loneliness due to ending old rela- } \\
\text { tionships (e.g. from time in } \\
\text { addiction) }\end{array}$ \\
\hline & SS & $\begin{array}{l}\text { Constrained bodily integrity and health, life, } \\
\text { affiliation, and control over one's environment. }\end{array}$ & $\begin{array}{l}\text { - No control over who one lives } \\
\text { with } \\
\text { - Co-living with people with com- } \\
\text { plex mental health and addic- } \\
\text { tions needs, and related } \\
\text { behaviours } \\
\text { - Not permitted to have visitations }\end{array}$ \\
\hline
\end{tabular}


Table 3. (Continued).

\begin{tabular}{|c|c|c|c|}
\hline $\begin{array}{l}\text { Theme } \\
\text { Sub-theme }\end{array}$ & Service & Capabilities Affordances/Constraints & Related service features \\
\hline \multirow[t]{2}{*}{$\begin{array}{l}\text { Community } \\
\text { interaction \& } \\
\text { stigma }\end{array}$} & $\mathrm{HF}$ & Facilitated affiliation & $\begin{array}{l}\text { - Opportunities for contact with } \\
\text { neighbours } \\
\text { - Rebuild previous ties in a familiar } \\
\text { community }\end{array}$ \\
\hline & SS & Constrained affiliation & $\begin{array}{l}\text { - Congregate living arrangements } \\
\text { highlighted situation to sur- } \\
\text { rounding community } \\
\text { - Prejudices held by community } \\
\text { members }\end{array}$ \\
\hline
\end{tabular}

I'd like to get into social work, social studies, I'd like to do that. I'd like to meet people and help out. (Ireland, HF561)

Examples of planning for the future are evident in these accounts, which is indicative of practical reason (see Table 2). The pursuit of education and employment are aligned with senses, imagination and thought, and family relationships are an important part of affiliation.

In contrast, some SS participants stayed in night shelters which opened from 9 p.m. to 9 a.m., which they described as an exhausting experience: "from morning to night, you're out 12 hours, you get more tired than going to work, you get tired both physically and mentally, because in your mind you're always thinking about many things" (Italy, SS166). Each day these SS participants had to worry about spending 12 hours of the day safe and dry, the source of their next meal, and returning to the shelter on time to get a bed. SS participants could not prioritise any capabilities besides bodily integrity and health: "if you can't meet your basic needs, right? You can't do things that make you happy" (Spain, HF1 19). However, HF participants were able to go beyond bodily integrity and health to pursue higher-order dimensions of practical reason, affiliation and senses, imagination and thought.

\section{Rules and Everyday Life}

HF participants described how, now that they had their own independence and home, their emotions were no longer blighted by fear and anxiety, and they could relax and freely engage in enjoyable pastimes. In this way, having a permanent home contributed to their play, emotions, and senses, imagination and thought capabilities: "for me, having fun is also like staying at home reading a book and drinking a beer. For me this is relaxing and fun" (Italy, HF1172). In contrast, SS participants described how their reliance on the service constrained their leisure time, and related play, affiliation, and control over environment capabilities:

Fun ... no, there are no such opportunities here. (Poland, SS205)

What I miss is freedom, especially in the evening, [...] being able to go out with friends, go out for dinner or take a walk and to not have the problem of that time I should come back. (Italy, SS539)

These SS participants were denied "freedom" and "fun" in exchange for a bed at the homeless shelter. Although participants were typically middle-aged, and some had jobs, they were in a situation where they had to comply with the paternalistic practices of service providers, or else be cast out on the street again, which constrained play, control 
over environment, affiliation and bodily integrity. Some even chose to stay on the street rather than comply with the constraints associated with shelters, as described in this HF participant's account of their past experience of living between shelters and the street: "[in shelters] they don't treat us like people. [...] which is why a lot of people prefer the street. I've been in hostels and preferred the street, a thousand times more" (Portugal, HF006). The impoverished quality of shelters is sometimes used as a way to discourage people from staying there long-term (Busch-Geertsema and Sahlin 2007) and evidently, it also serves to keep people out and living on the street, with related deprivations in bodily integrity, health and life.

For SS participants, restrictions existed around food, which they described as poor quality, only permitted during designated mealtimes, and which did not meet their dietary requirements: "they give a little bag of dinner at night, a little carcass and a yogurt" (Portugal, SS002). Having portable appliances like hot plates, or kettles was prohibited in many SS settings. For example, one participant described how the service users must be supervised when using a communal microwave, which made them feel infantilised: "By preventing us from doing this, it is as if they are saying 'you are inept, you are not able to do things and we must do them for you'" (Italy, SS212). Rules that prevented services users from carrying out basic everyday tasks independently made them feel patronised, and restricted their ability to learn and practice independent living skills, and this constrained the capabilities of practical reason, control over environment, emotions and affiliation.

In contrast, HF participants spoke appreciatively about the basic comforts of safety, privacy and facilities for cooking and hygiene, which are important for bodily health and bodily integrity capabilities: "I'm more healthy, I feed myself better" (Portugal, HF010). HF participants also felt empowered by the act of managing their household and daily life, as demonstrated in the following participant's account: "money management, paying rent and bills, keeping the house tidy, washing clothes, cooking are all actions on which you feel you can exercise power, which are part of your everyday life" (Italy, HF172). In contrast to the experiences of participants in SS, who felt humiliated because service providers did not trust them to carry out daily living tasks independently, HF participants were free to enact the role of homemaker, through everyday tasks which helped them to feel dignified, competent, and empowered. The transformation from the role of service recipient to homemaker and associated feelings of power, dignity and competence align with affiliation, emotions and practical reason. For example, affiliation not only refers to relationships with others but one's relationship with oneself: to have self-respect and be free of humiliation (see Table 2). Feelings of "power" versus feelings of ineptitude contributed to emotions and practical reason. Having control over one's home and carrying out everyday tasks, in contrast to being controlled in an institutional setting, and struggling to address one's basic needs signified life, and control over environment capabilities.

\section{Transformative Impact of Home}

SS participants described navigating complicated systems of social and housing services as well as dealing with their own mental and physical health problems, which meant they had little capacity to develop any capabilities besides bodily integrity and health. SS participants described how their entire day consisted of trying to get food and money, and this left little headspace for positive emotions or personal development: "you are busy every day looking for food, living on little money, doing odd jobs to earn some money" 
(Netherlands, SS505). However, through the provision of housing and wraparound supports, HF took participants out of homelessness and placed them in housing in the community, and this transformed their capacity to experience joy and to live a good life: "[HF] changed my life, my lifestyle, my health, everything I am" (Spain, HF119).

Participants living in SS were still waiting for the transformative impact of home while they cycled in and out human service agencies and institutions. Lack of home meant SS service users were merely existing rather than flourishing, as shown in the following extract: "Health is bad, life is bad. I am homeless, without a flat, without anything" (Poland, SS504). Hopelessness permeated participants' accounts of being without any options and feeling trapped in a selfperpetuating services system. For example, in one SS participant's account, after interviewing for a job they learned that they could not be hired without a fixed address: "On the one hand, the municipality [...] pushes you to look for work if you live on the street, while an employer may not even give you a contract as long as you have no address" (Netherlands, SS505). Trapped between conflicting administrative demands, this participant experienced external capabilities constraints at a legal and socio-political level which, ironically, sustained their economic dependence on the state, and reinforced their sense of powerlessness and lack of political and material control over their environment. In contrast, for HF participants, freedoms and functionings that were previously never possible were now easily fulfilled through having a home, especially in life, emotions, and bodily health and integrity.

\section{Relational Impact of Living Arrangements}

Homelessness consists of a relational deficit because being without a home is to be without a space to enact relational activities (Mallett et al. 2010). Relationship breakdown is both a cause and consequence of homelessness (e.g. Busch-Geertsema and Fitzpatrick 2008), therefore rebuilding valued relationships is integral to rebuilding a well-lived life.

\section{Familial and Intimate Relationships}

Having a home, especially in close proximity to loved ones, gave HF participants the freedom to regularly participate in family life, as described in the following excerpt: "I look after the kids too. I'd cook the dinner there for the whole lot of us" (Ireland, HF326). Couples in HF were free to live together, which is often not possible in SS: "[my romantic partner] moved in too, and then we got a normal life once we had a house" (Portugal, HF010). Participants greatly appreciated the daily activities of "normal life" and in this way, having a home facilitated their life, and control over environment. Being with family meant "everything" (Ireland, HF346) to participants, who were able to rebuild valuable relationships after lengthy periods of absenteeism during episodes of homelessness. For participants in SS, it was emotionally painful to be separated from their children, as illustrated here: "I hadn't seen the kids for a while, [...] when I got back seeing them, after the first visit when the kids were leaving, the kids said, "bye", and gave me a kiss [...], I felt like crying" (Ireland, SS329). Therefore, through offering participants a place to be part of their family, HF not only afforded affiliation, but also life and emotions.

Paternalistic SS rules prevented participants from spending quality time with family. Most were not permitted to have their children stay with them, "you're not allowed kids here" (Ireland, SS329), and time away from the service was regulated: "I visited my brother in Milan [...] but I had to get written permission for the three days" (Italy, SS539). Not only 
did these rules prevent participants from freely expressing valued roles and engaging in activities with family members, they made participants feel ashamed to see family: "I have a child, and I avoid seeing him [here]" (France, SS208). The rule-bound delivery of SS made it difficult for participants to maintain important family relationships, which was constraining for participants' life, emotions, affiliation and control over environment.

Freedom to have intimate relationships and express one's sexuality is an important element of bodily integrity (Nussbaum 2011), and freedom to feel and express love and pleasure underlies emotions, and senses, imagination, and thought. SS participants reported that their living situation was not appropriate for having intimate relationships: "In the shelter, absolutely no [...] 'that' cannot be done, otherwise it's messy. Not there" (Italy, SS166). Features of the living space such as curfew, lack of privacy, and regulated visitations were described as constraints on participants' romantic relationships and affiliations. One SS participant described experiencing homophobia from co-residents: "I'm being bullied a lot, like, because of my sexuality" (Ireland, SS108). Not only did this participant experience the SS environment as constraining for intimate relationships, it was also threatening and prevented them from expressing their true self, which served to further compound restrictions on bodily integrity, affiliations, emotions, and senses, imagination, and thought.

\section{Friendship}

SS participants described daily life rooming with people who were violent, disruptive, and often intoxicated from alcohol or drugs, a situation which constrained their bodily integrity and health, life, affiliation, and control over environment, as shown in this account: "There are always crazy people here. There are people with mental issues, there are people with abusive behaviours" (Ireland, SS117). SS participants were constrained in participating in activities with friends and the wider community due to the rules of SS: "here we cannot invite anyone from outside" (Italy, SS212). In the absence of a network of friends outside of the service, participants in SS bonded with others in similar circumstances, like "fellow tramps" (Netherlands, SS505). SS placed limitations on the kinds of interactions participants could have, such that participants' lack of control over environment exacerbated the constraints they experienced on affiliation.

HF participants had control over who they interacted with, and many chose to keep their friend group small. HF participants were reluctant to interact with people from their past out of fear that they would pick up old habits like gambling or drug use: "I was afraid to break what I had already rebuilt" (France, HF322). These participants expressed that they wished to "move on" (Ireland, HF456) from their past lives and start fresh. However, as participants distanced themselves from old acquaintances, some felt increasingly lonely: "sometimes you get a bit lonely" (Ireland, HF456). HF participants were eager to expand their social networks and recognised ways to meet new people, for example, through employment or education, but found that it was not easy to do so. For example, some participants suffered physical health issues that limited their capacity to work and meet new people: "I don't know if I'll be able to work until retirement because of my back pain" (France, HF505), and others were prevented from going out with friends due to financial limitations: "last weekend my friends went to the beach [...]. I would have gone [...] only that I can't afford gasoline, hotel and things like that" (Italy, HF533). Although HF facilitated participants' 
control over environment and freedom to exercise affiliations, participants struggled to establish new relationships because of other extrinsic constraints placed on them.

\section{Community Interaction and Stigma}

Ware and colleagues (Ware et al. 2007) described adults experiencing homelessness as "in" the community but not "of" it, meaning that although they might exist in the community, they are still alienated from its social milieu, and this was evident in participants' accounts in the present study. SS participants spoke about the stigma attached to where they lived, and how members of the surrounding community held prejudices about them:

It's just the stigma [...] of this place and people see you, do you know? They just think, 'Ah, he's in there. He must be on this or that [drug]'. (Ireland, SS329)

Here we are excluded. [...] this place is known for having people who were in jail ... who I call, the invisible men. (Italy, SS539)

Where adults in need of shelter are housed in congregate settings, it makes their situation more visible to surrounding community members, contributes to stigma, and results in feelings of shame and alienation, which are detrimental for affiliation.

In contrast, the normalised living arrangements provided in HF allowed participants to regularly engage with neighbours and community resources: "I feel embedded in society, I have projects, I have goals, I have a life equal to others" (Portugal, HF002). Based on this account, having a home in the community facilitated this participant to become "of" the community. Having a home in a familiar neighbourhood was particularly advantageous for participants' community integration, a functioning of affiliation: "This was already my area when I was a kid and for this reason, I know so many people, I have many friends" (Italy, HF963). Living in a familiar neighbourhood may help to alleviate feelings of loneliness sometimes associated with transitions to independent housing, and to promote the development of affiliation.

\section{Discussion}

In this study, we used the capabilities approach to portray the experiences of homeless service users in SS and HF programmes in Europe. Findings confirm that home, or a lack thereof, is a mechanism that can act to enable or constrain the functions required for a well-lived life. Dimensions of ontological security (Padgett 2007; Dupuis and Thorns 1998) including constancy, privacy, routine, and a secure base for identity construction, were evident in HF services users' accounts of home. HF service users were at a more advanced stage of realising their capabilities compared to their SS counterparts. SS services users were denied the freedom to exercise their capabilities on multiple dimensions and at multiple ecological levels, including at the individual level (e.g. personal safety), and legal level (e.g. no legal address). The central capabilities are based on the minimum standards required to live a life worthy of human dignity, and based on European service users' experiences, staircase services do not even address basic bodily health and integrity, and completely limit control over one's environment. As long as the staircase model continues to be the dominant mode of 
care for people in homelessness in Europe, service users will continue to be unfairly treated as if they are undeserving of a dignified life.

Wolff and de-Shalit (Wolff and de-Shalit 2007, 122) described functionings "which spread their good effects over several categories, either directly or by reducing risk to the other functionings", as fertile functionings, and home was a fertile functioning experienced by HF service users. Home was more than simply shelter, it offered a sense of belonging, identity and security (Dupuis and Thorns 1998; Batterham 2019; Mallett et al. 2010) which pervaded services users' lives and allowed them to expand the things they were capable of doing, like gain education, employment, express their identity, and reconnect with family. Similar to King's (King 2003) contention, we found that home gave service users a place where they could exist free from the surveillance and interference of others and construct meaningful aspects of a well-lived life. For adults experiencing homelessness, choice over housing is associated with fewer psychiatric symptoms and better quality of life (Greenwood et al. 2005; Greenwood and Manning 2017; Nelson et al. 2007), and findings from this study captured a transformation that took place in participants' lives when they moved out of a low-choice situation in SS to a high-choice situation in HF. When given a secure base, tailored supports, and all the associated freedoms of home, service users began to exert control over their lives. Even service users with ongoing mental health or addiction issues successfully carried out household tasks and took pride in their homes, a finding that complements existing evidence for the suitability of HF for adults with serious mental illness (e.g. Pearson, Montgomery, and Locke 2009; Tsemberis, Gulcur, and Nakae 2004).

Wolff and de-Shalit (Wolff and de-Shalit 2007, 138) proposed that corrosive disadvantage was "something whose absence or insecurity will lead to problems with other functionings", and the absence of a home was a corrosive disadvantage experienced by service users in SS. In SS, service users can exercise their bodily health and integrity, but simultaneously, their bodily integrity is constantly threatened by a grave lack of security and inadequate facilities. In SS, control over one's environment is never realised. Instability prevents people from feeling at ease in their space, or accruing valued personal belongings, which are psychological aspects of home (Padgett 2007). Our findings line up with others (e.g. Rivlin and Moore 2001) who argue that service users cannot exercise the physical, emotional, and cognitive aspects of home while living in unsuitable temporary accommodation, which serve only to compound the stress of being without a home.

To the best of our knowledge, this study is the first of its kind to apply the capabilities approach to the experiences of homeless service users in eight European countries. Our findings expand existing literature that brings together capabilities and homeless service users' experiences (e.g. Nicholls 2010; Smith 2010; Kerman and Sylvestre 2019). The HF model operates under the assumption that service users will set goals for themselves when given the chance (Shinn 2015), and our findings support this. Participants in HF planned for the future, preserved the progress they had made in respect of their housing situation, and identified and pursued meaningful goals. However, participants in SS were unable to make many plans for the future because of the impermanence of their living situation.

Some HF participants reported that they sometimes felt lonely, and others identified extrinsic constraints on their ability to meet new people and maintain friendships, and previous research has indicated that it can be difficult for HF services users to adjust to living alone, especially after living in busy congregate settings (e.g. Yanos, Barrow, and Tsemberis 
2004). On the contrary, other research has indicated that congregate living settings can be inherently lonely places, and that the loneliness of independent living was often perceived as unproblematic, especially for those who enjoyed the freedom of solitude (Piat, Sabetti, and Padgett 2018; Piat, Seida, and Padgett 2019). In both studies by Piat, Sabetti, and Padgett $(2018,2019)$, participants perceived feeling lonely as part of the transition to a normalised living situation, and felt that they were equipped to deal with it. Similarly, in our study, participants described ways they alleviated loneliness, such as joining an interest group, or getting a pet, and being in their own home meant that these options were feasible for them. Our findings also indicated that feelings of isolation may be mitigated if services users choose housing in a familiar neighbourhood, such as where they grew up. However, this may be more feasible for HF programmes in smaller cities where housing supply and demand are less pressured, compared to densely populated cities.

The capabilities dimension of other species was absent from our findings, and this was because participants did not give the same emphasis, depth or meaning to this capability dimension compared to the other dimensions discussed in this article. Where participants did ascribe meaning to pet ownership, it suggested that having a pet may serve to alleviate the loneliness sometimes experienced while living alone, and this is consistent with research that has highlighted pet ownership as a source of love and companionship for adults experiencing homelessness (e.g. Irvine 2013). However, other research (e.g. Rhoades, Winetrobe, and Rice 2015) with homeless youth has indicated that having a pet can create difficulties in accessing shelters, and limit available housing options. Future research on other species could clarify the constraining and affording influence of pet ownership for homeless service users' capabilities.

Additional research from the HOME_EU study has identified statistically significant differences between the capabilities of HF and SS service users. Results from a quantitative study of homeless service users' capabilities (Greenwood, Manning, O'Shaughnessy, Vargas-Moniz, et al. 2020) indicate what differences in capabilities exist between HF and SS, while the results of this study build on this to indicate how SS and HF shape service users' capabilities. Future research could examine specific features of HF and SS delivery to explore whether we can draw causal inferences about the capabilities-enhancing or constraining features of different models of homeless service delivery.

In some situations, SS, in the form of emergency shelter can provide protection from the elements for people who would otherwise sleep on the street, however, the shelter provided by SS was inadequate and failed to address bodily health and integrity, life or affiliation, and many other elements of a dignified life. Similar to Nicholls (2010) we found that SS services users often paradoxically found themselves exercising one capability set at the expense of another, or, finding that one realised capability was being undermined by their living situation. Evidently, this trade-off of capabilities was intolerable for the participants who preferred to stay on the street rather than in their local homeless shelter.

Based on our findings we conclude that HF is consistent with a capabilities approach to social justice. As part of the United Nations Sustainable Development Goals (European Commission 2019) and European Pillar of Social Rights (European Commission 2017) each EU member state committed to guarantee access to adequate housing for its citizens and services for those experiencing homelessness. If the 
political leaders of these EU member states are serious about ending long-term homelessness, then we recommend that policymakers consider a capabilitiesinformed approach. Staircase services are failing EU citizens in homeless situations, who are being denied the basic right to adequate housing and protection from violence. Homelessness is a crisis situation and emergency accommodation is sometimes warranted, however investment solely in temporary services will not put an end to homelessness in European cities. We urge policy makers and political stakeholders to respond to persistent and prevailing homelessness as a housing issue, and to consider the Housing First model as a solution for ending homelessness. Previous research has indicated that $\mathrm{HF}$ is more successful and cost-effective than staircase services (e.g. Aubry, Nelson, and Tsemberis 2015; Gulcur et al. 2003; Atherton and Nicholls 2008) and our findings suggest that it also allows service users to enact their human right to a home and to regain a life worthy of human dignity.

\section{Conclusion}

Our objective was to identify and compare the constraints and affordances on capabilities experienced by service users in SS and HF programmes in Europe. Through Housing First, service users gained a home, which allowed them to go beyond addressing their bodily health and integrity to expand their capabilities sets, and this had far-reaching consequences for their recovery from periods of homelessness. Service users in SS could rarely enact freedoms beyond addressing bodily health and integrity, which meant that their actualisation was stifled by their living situation. Findings confirm that HF service users experience the service as capability-enhancing, and this reinforces the importance of home as a base where people can enact their freedoms including that of stability, identity, privacy and routine. Although SS services offered shelter and basic needs facilities, this was often poor quality and did not serve to replace the affective and relational aspects of home. Based on participants' accounts we postulate that long-term stays in SS services are inappropriate and damaging for service users' capabilities.

The capabilities approach (Sen 2005) highlights the minimal standards for a life worthy of human dignity, and service users in staircase services are unable to achieve the central capabilities they would otherwise achieve in Housing First. We urge stakeholders and policymakers in the area of homelessness redress to work to expunge this unfairness and increase Housing First programmes and access to adequate housing for those who are denied this basic human right.

\section{Acknowledgments}

HOME-EU (Horizon 2020 GA/726997) consortium study group: José Ornelas (Principal Investigator), Maria J.Vargas-Moniz, Maria F Jorge-Monteiro (APPsyCl - Applied Psychology Research Center Capabilities and Inclusion, ISPA-Instituto Universitário, Rua Jardim do Tabaco, 34, 1149-041 Lisboa, Portugal); Ronni M. Greenwood, Rachel M. Manning, Branagh O'Shaughnessy (Department of Psychology, University of Limerick, Limerick, V94 T9PX, Ireland); Inês Almas, Teresa Duarte (AEIPS - The Association for Study and Psychosocial Integration; Housing First project: Casas Primeiro, Av. António José de Almeida, 26, 1000-043 Lisboa, Portugal); Francesca Disperati, Marta Gaboardi, Michela Lenzi, Massimo Santinello, Alessio Vieno (Department of Developmental and Social Psychology, University of Padova, Via Venezia, 8 -35131 Padova, Italy); Rita P. Marques, 
Maria Carmona, Américo Nave (Crescer-Community Intervention Association, Bairro Qta Cabrinha 3-E/F 1300-906 Lisboa, Portugal); Freek Spinnewijn (FEANTSA, European Federation of National Organisations Working with the Homeless, Chausse de Louvain 194 Bruxelles 1210, Belgique); Roberto Bernad, Borja Rivero, Martin Julián (Rais Fundación, C/Ardemans 42, 28028 Madrid, Spain); Anna Bokszczanin, Barbara Zmaczynska-Witek, Skałacka Katarzyna, Aleksandra Rogowska (Institute of Psychology, Opole University, Pl. Staszica 1, 45-052 Opole, Poland); Sandra Schel, Yvonne Peters, Tessa van Loenen, Liselotte Raben, Judith R. Wolf (Radboud university medical center, Radboud Institute for Health Sciences, Impuls - Netherlands Center for Social Care Research, Nijmegen, The Netherlands); Ulla Beijer, Mats Blid, Hakan Kallmen (STAD, Stockholm Center for Psychiatry Research and Education, Karolinska Institutet, Norra Stationsgatan 69, 113 64 Stockholm, Sweden); Teresa Bispo, Tiago Cruz, Carla Pereira (Câmara Municipal de Lisboa [The Lisboa City Council], Praça do Município 38, 1100-038 Lisboa, Portugal); Pascal Auquier, Junie M. Petit (Aix-Marseille Univ, School of medicine-La timone Medical Campus, EA3279 CEReSSHealth Service Research and Quality of Life Center, 27 Boulevard Jean Moulin, 13385 Marseille, France), Sandrine Loubière, Aurélie Tinland (Department of Research and Innovation, Support Unit for clinical research and economic evaluation, Assistance Publique-Hôpitaux de Marseille, 27 Boulevard Jean Moulin, 13385 Marseille, France).

We would like to thank the participants who contributed their time, and shared their experiences as part of this study. We would also like to acknowledge the contributions of Amy Molloy, Niamh O'Neill, and Oisín Cross to the transcription, coding, and data management stages of this study.

\section{Disclosure statement}

No potential conflict of interest was reported by the authors.

\section{Funding}

This work was supported by the Horizon 2020 Framework Programme [GA/726997].

\section{ORCID}

Branagh R. O' Shaughnessy (DD http://orcid.org/0000-0003-4417-7273

Rachel M. Manning (D) http://orcid.org/0000-0003-2254-1484

Ronni Michelle Greenwood (iD http://orcid.org/0000-0002-1456-0493

Maria João Vargas-Moniz (D) http://orcid.org/0000-0002-4875-9118

Sandrine Loubière (D) http://orcid.org/0000-0001-6715-1223

Marta Gaboardi (D) http://orcid.org/0000-0003-2263-1359

Judith R. Wolf (D) http://orcid.org/0000-0001-7106-9142

Anna Bokszczanin (D) http://orcid.org/0000-0002-0499-8133

Roberto Bernad (D) http://orcid.org/0000-0002-6878-1419

Mats Blid (D) http://orcid.org/0000-0002-1203-9872

Jose Ornelas (D) http://orcid.org/0000-0002-8972-7518

\section{References}

Atherton, I., and C. M. Nicholls. 2008. "'Housing First'as a Means of Addressing Multiple Needs and Homelessness." European Journal of Homelessness 2: 289-303.

Aubry, T., G. Nelson, and S. Tsemberis. 2015. "Housing First for People with Severe Mental Illness Who are Homeless: A Review of the Research and Findings from the at Home-Chez Soi Demonstration Project." The Canadian Journal of Psychiatry 60 (11): 467-474. doi:10.1177/ 070674371506001102. 
Batterham, D. 2019. "Homelessness as Capability Deprivation: A Conceptual Model." Housing, Theory and Society 36 (3): 274-297. doi:10.1080/14036096.2018.1481142.

Bazeley, P. 2009. "Analysing Qualitative Data: More than 'Identifying Themes'." Malaysian Journal of Qualitative Research 2 (2): 6-22.

Beaton, D. E., C. Bombardier, F. Guillemin, and M. B. Ferraz. 2000. "Guidelines for the Process of Cross-Cultural Adaptation of Self-Report Measures." Spine 25 (24): 3186-3191. doi:10.1097/ 00007632-200012150-00014.

Braun, V., and V. Clarke. 2006. "Using Thematic Analysis in Psychology." Qualitative Research in Psychology 3 (2): 77-101. doi:10.1191/1478088706qp063oa.

Busch-Geertsema, V. 2014. "Housing First Europe-results of a European Social Experimentation Project." European Journal of Homelessness 8: 13-29.

Busch-Geertsema, V., and I. Sahlin. 2007. "The Role of Hostels and Temporary Accommodation." European Journal of Homelessness 1: 67-93.

Busch-Geertsema, V., and S. Fitzpatrick. 2008. "Effective Homelessness Prevention? Explaining Reductions in Homelessness in Germany and England." European Journal of Homelessness 2: 69-95.

Byrne, T., and D. P. Culhane. 2011. "The Right to Housing: An Effective Means for Addressing Homelessness." University of Pennsylvania Journal of Law and Social Change 14 (3): 379-390.

Centre for Social Justice. 2017. "Housing First: Housing-led Solutions to Rough Sleeping and Homelessness." The Centre for Social Justice, March 13. https://www.centreforsocialjustice.org. uk/library/housing-first-housing-led-solutions-rough-sleeping-homelessness

Dupuis, A., and D. C. Thorns. 1998. "Home, Home Ownership and the Search for Ontological Security." The Sociological Review 46 (1): 24-47. doi:10.1111/1467-954X.00088.

European Commission. 2017. "Commission Recommendation of 26.4.2017 on the European Pillar of Social Rights."

European Commission. 2019. "Sustainable Development Goals.".

Evangelista, G. F. 2010. "Poverty, Homelessness and Freedom: An Approach from the Capabilities Theory." European Journal of Homelessness 4: 189-203.

Geertz, C. 1973. The Interpretation of Cultures. Vol. 5019. New York: Basic books.

Goodman, L. A., M. A. Dutton, and M. Harris. 1995. "Episodically Homeless Women with Serious Mental Illness: Prevalence of Physical and Sexual Assault." American Journal of Orthopsychiatry 65 (4): 468-478. doi:10.1037/h0079669.

Greenwood, R. M., N. J. Schaefer-McDaniel, G. Winkel, and S. J. Tsemberis. 2005. “Decreasing Psychiatric Symptoms by Increasing Choice in Services for Adults with Histories of Homelessness." American Journal of Community Psychology 36 (3-4): 223-238. doi:10.1007/s10464-005-8617-z.

Greenwood, R. M., and R. M. Manning. 2017. "Mastery Matters: Consumer Choice, Psychiatric Symptoms and Problematic Substance Use among Adults with Histories of Homelessness." Health \& Social Care in the Community 25 (3): 1050-1060. doi:10.1111/hsc.12405.

Greenwood, R. M., R. M. Manning, B. R. O'Shaughnessy, M. J. Vargas-Moniz, P. Auquier, M. Lenzi, J. R. Wolf, et al. (2020). "Experiences of Homeless Services as Capabilities-Enhancing in Housing First versus Traditional Services: The Mediating Roles of Consumer Choice and Housing Quality". Unpublished manuscript. University of Limerick.

Greenwood, R. M., R. M. Manning, B. R. O'Shaughnessy, O. Cross, M. J. Vargas-Moniz, and P. Auquier et al. 2020. "Comparison Of Housing First and Traditional Homeless Service Users in Eight European Countries: Protocol for a Mixed Methods, Multi-site Study." JMIR Research Protocols 9 (2): e14584.

Gulcur, L., A. Stefancic, M. Shinn, S. Tsemberis, and S. N. Fischer. 2003. "Housing, Hospitalization, and Cost Outcomes for Homeless Individuals with Psychiatric Disabilities Participating in Continuum of Care and Housing First Programmes." Journal of Community \& Applied Social Psychology 13 (2): 171-186. doi:10.1002/casp.723.

Hopper, K., J. Jost, T. Hay, S. Welber, and G. Haugland. 1997. “Homelessness, Severe Mental Illness, and the Institutional Circuit." Psychiatric Services 48 (5): 659-665. 
Hwang, S. W., R. Wilkins, M. Tjepkema, P. J. O'Campo, and J. R. Dunn. 2009. "Mortality among Residents of Shelters, Rooming Houses, and Hotels in Canada: 11 Year Follow-up Study." BMJ 339 (oct26 3): b4036. doi:10.1136/bmj.b4036.

Irvine, L. 2013. "Animals as Lifechangers and Lifesavers: Pets in the Redemption Narratives of Homeless People." Journal of Contemporary Ethnography 42 (1): 3-30. doi:10.1177/0891241612456550.

Kerman, N., and J. Sylvestre. 2019. "Surviving versus Living Life: Capabilities and Service Use among Adults with Mental Health Problems and Histories of Homelessness." Health \& Social Care in the Community Advance online publication. doi:10.1111/hsc.12873.

King, P. 2003. A Social Philosophy of Housing. Aldershot: Ashgate.

Lyon-Callo, V. 2000. "Medicalizing Homelessness: The Production of Self-Blame and Self-Governing within Homeless Shelters." Medical Anthropology Quarterly 14 (3): 328-345. doi:10.1525/ maq.2000.14.3.328.

Mallett, S., D. Rosenthal, D. Keys, and R. Averill. 2010. Moving Out, Moving On: Young People's Pathways in and through Homelessness. London; New York: Routledge.

Miles, M. B., A. Michael Huberman, and J. Saldana. 2014. Qualitative Data Analysis: A Methods Sourcebook. 3rd ed. London: Sage.

Nelson, G., J. Sylvestre, T. Aubry, L. George, and J. Trainor. 2007. “Housing Choice and Control, Housing Quality, and Control over Professional Support as Contributors to the Subjective Quality of Life and Community Adaptation of People with Severe Mental Illness." Administration and Policy in Mental Health and Mental Health Services Research 34 (2): 89-100. doi:10.1007/s10488-006-0083-x.

Nicholls, C. M. 2010. "Housing, Homelessness and Capabilities." Housing, Theory and Society 27 (1): 23-41. doi:10.1080/14036090902764588.

Nussbaum, M. C. 2011. Creating Capabilities: The Human Development Approach. Cambridge, MA and London, England: Harvard University Press.

Padgett, D. K. 2007. "There's No Place like (A) Home: Ontological Security among Persons with Serious Mental Illness in the United States." Social Science \& Medicine 64 (9): 1925-1936. doi:10.1016/j.socscimed.2007.02.011.

Pearson, C., A. E. Montgomery, and G. Locke. 2009. "Housing Stability among Homeless Individuals with Serious Mental Illness Participating in Housing First Programs." Journal of Community Psychology 37 (3): 404-417. doi:10.1002/jcop.20303.

Piat, M., J. Sabetti, and D. Padgett. 2018. "Supported Housing for Adults with Psychiatric Disabilities: How tenants Confront the Problem of Loneliness." Health \& Social Care in the Community 26 (2): 191-198. doi:10.1111/hsc.12508.

Piat, M., K. Seida, and D. Padgett. 2019. "Choice and Personal Recovery for People with Serious Mental Illness Living in Supported Housing." Journal of Mental Health 1-8. doi:10.1080/ 09638237.2019.1581338.

Rhoades, H., H. Winetrobe, and E. Rice. 2015. "Pet Ownership among Homeless Youth: Associations with Mental Health, Service Utilization and Housing Status." Child Psychiatry and Human Development 46 (2): 237-244. doi:10.1007/s10578-014-0463-5.

Ridgway, P., and A. M. Zipple. 1990. "The Paradigm Shift in Residential Services: From the Linear Continuum to Supported Housing Approaches." Psychosocial Rehabilitation Journal 13 (4): 11-31. doi:10.1037/h0099479.

Rivlin, L. G., and J. Moore. 2001. "Home-Making: Supports and Barriers to the Process of Home." Journal of Social Distress and the Homeless 10 (4): 323-336. doi:10.1023/A:1011624008762.

Roncarati, J. S., T. P. Baggett, J. J. O'Connell, S. W. Hwang, E. Francis Cook, N. Krieger, and G. Sorensen. 2018. "Mortality among Unsheltered Homeless Adults in Boston, Massachusetts, 2000-2009." JAMA Internal Medicine 178 (9): 1242-1248. doi:10.1001/jamainternmed.2018.2924.

Sahlin, I. 2005. "THE STAIRCASE OF TRANSITION: Survival through Failure." Innovation: The European Journal of Social Science Research 18 (2): 115-136.

Sen, A. 1980. "Equality of What?" In Tanner Lectures on Human Values, edited by McMurrin, 197-220. Cambridge: Cambridge University Press.

Sen, A. 1992. Inequality Re-examined. Oxford: Clarendon Press.

Sen, A. 1999. Development as Freedom. New York: Knopf. 
Sen, A. 2004. "Capabilities, Lists, and Public Reason: Continuing the Conversation." Feminist Economics 10 (3): 77-80. doi:10.1080/1354570042000315163.

Sen, A. 2005. "Human Rights and Capabilities." Journal of Human Development 6 (2): 151-166. doi:10.1080/14649880500120491.

Shinn, M. 2015. "Community Psychology and the Capabilities Approach." American Journal of Community Psychology 55 (3-4): 243-252. doi:10.1007/s10464-015-9713-3.

Smith, J. 2010. "Capabilities and Resilience among People Using Homeless Services." Housing, Care and Support 13 (1): 9-18. doi:10.5042/hcs.2010.0308.

Smith, M. L., and C. Seward. 2009. "The Relational Ontology of Amartya Sen's Capability Approach: Incorporating Social and Individual Causes." Journal of Human Development and Capabilities 10 (2): 213-235. doi:10.1080/19452820902940927.

Stark, L. R. 1994. "The Shelter as "Total Institution": An Organizational Barrier to Remedying Homelessness." American Behavioral Scientist 37 (4): 553-562. doi:10.1177/0002764294037004008.

Tanekenov, A., S. Fitzpatrick, and S. Johnsen. 2018. "Empowerment, Capabilities and Homelessness: The Limitations of Employment-focused Social Enterprises in Addressing Complex Needs." Housing, Theory and Society 35 (1): 137-155. doi:10.1080/14036096.2017.1290676.

Team, Homeless Link Policy and Research. 2015. "Housing First' or 'Housing Led'? the Current Picture of Housing First in England." Homeless Link. https://www.homeless.org.uk/sites/default/files/siteattachments/Housing\%20First\%20or\%20Housing\%20Led.pdf

Tsemberis, S. 2010. "Housing First: Ending Homelessness, Promoting Recovery and Reducing Costs." In How to House the Homeless, edited by I. Gould Ellen and B. O'Flaherty, 37-56. New York: Russell Sage Foundation.

Tsemberis, S., L. Gulcur, and M. Nakae. 2004. "Housing First, Consumer Choice, and Harm Reduction for Homeless Individuals with a Dual Diagnosis." American Journal of Public Health 94 (4): 651-656. doi:10.2105/AJPH.94.4.651.

Tsemberis, S., and R. F. Eisenberg. 2000. "Pathways to Housing: Supported Housing for Street-Dwelling Homeless Individuals with Psychiatric Disabilities." Psychiatric Services 51 (4): 487-493. doi:10.1176/appi.ps.51.4.487.

Ware, N. C., K. Hopper, T. Tugenberg, B. Dickey, and D. Fisher. 2007. “Connectedness and Citizenship: Redefining Social Integration." Psychiatric Services 58 (4): 469-474. doi:10.1176/ps.2007.58.4.469.

Wolff, J., and A. de-Shalit. 2007. Disadvantage. Oxford: Oxford University Press.

Yanos, P. T., S. M. Barrow, and S. Tsemberis. 2004. "Community Integration in the Early Phase of Housing among Homeless Persons Diagnosed with Severe Mental Illness: Successes and Challenges." Community Mental Health Journal 40 (2): 133-150. doi:10.1023/B: COMH.0000022733.12858.cb. 